\title{
Two TheOries OF TransparenCy
}

\author{
EDWARd W. AVERILl \& Joseph GotTlieb \\ Texas Tech University \\ Forthcoming in Erkenntnis \\ Penultimate draft. Please cite published version.
}

\begin{abstract}
Perceptual experience is often said to be transparent; that is, when we have a perceptual experience we seem to be aware of properties of the objects around us, and never seem to be aware of properties of the experience itself. This is a (purported) introspective fact. It is also often said that we can infer a metaphysical fact from this introspective fact, e.g. a fact about the nature of perceptual experience. A transparency theory fills in the details for these two facts, and bridges the gap between them. Our aim in this paper is three-fold: to scrutinize Michael Tye's transparency theory $(2002,2009$, 2014a), introduce a new transparency theory, and advance a meta-theoretical hypothesis about the interest and import of transparency theories in general.
\end{abstract}

\section{Transparency Theories}

You are at a weekend barbecue. Someone is grilling onions. This occasions an olfactory experience of grilled onions. Shortly thereafter, your friend remarks about the beautiful early evening sky. This draws your attention skyward, occasioning a visual experience of a sunset. When you introspect these experiences, you are 
aware of certain phenomenal properties—-henceforth, 'p-properties. ${ }^{1}$ Unlike occurring on the weekend, these properties type your experiences by what it is like to have them. They characterize an aspect of that experience's phenomenal character, which captures the entirety of what it is like to undergo that experience. The p-properties I am aware of when I have an experience of a sunset are different from those you are aware of when you have an olfactory experience of grilled onions. These experiences thus have distinct phenomenal characters; they fall into distinct phenomenal kinds.

The going consensus is that introspection reveals that these p-properties seem to be ordinary external properties, properties that physical objects can have. Arguably the most famous expression of this consensus comes from Gilbert Harman:

When Eloise sees a tree before her, the colors she experiences are all experienced as features of the tree and its surroundings. None of them are experienced as intrinsic features of her experience. Nor does she experience any features of anything as intrinsic features of her experiences. And that is true of you too. There is nothing special about Eloise's visual experience. When you see a tree, you do not experience any features as intrinsic features of your experience. Look at a tree and try to turn your attention to intrinsic features of your visual experience. I predict you will find that the only features there to turn your attention to will be features of the presented tree...(1990: 39)

Harman is claiming that experience is transparent. ${ }^{2}$ When Eloise sees the tree and its leaves, she has an experience. She is, let us say, aware of phenomenal greenness - that p-property associated with my normal experiences of some finegrained shade of greenness. But, as Harman notes, the property she sees is seen as a property of the tree, not as a property of her experience of the tree. Phenomenal

\footnotetext{
${ }^{1}$ The term 'phenomenal property' is occasionally used to denote a property that is mental by stipulation. On our usage this is not built in.

${ }^{2}$ The notion of transparency arguably originated with G.E. Moore (1922), although it's unclear whether Moore actually endorsed transparency. See Kind (2003) and Stoljar (2004) for discussion.
} 
green is thus plausibly just ordinary green. Indeed, she doesn't really seem to be aware of her experience at all. ${ }^{3}$ Such is the basic idea behind transparency. It is supposed to generalize. And it is supposed to yield an interesting metaphysical lesson about the relationship between an experience and the p-properties that type an experience by what it is like to have it. Yet the precise nature of that lesson is unsettled.

We seek to make headway on this issue. Let a transparency theory be the conjunction of three claims:

An Introspective Claim A claim about the way p-properties seem to a subject upon introspection-e.g. that they seem to be properties of objects in the subject's ambient environment, not properties of the experience itself.

A Metaphysical Claim A claim concerning a disconnect between p-properties and our experiences of them-e.g. that p-properties are not properties of experience.

An Auxiliary Claim A claim that facilitates the inference from the introspective claim to the metaphysical claim.

There is a strict reading of 'what does it mean to say that experience is transparent?' where permissible answers are confined to the way things seem upon introspection. This would identify the thesis of transparency with the introspective claim. The problem is that this way of capturing the debate would leave out much that is interesting, and where much of the action is: finding an auxiliary claim that allow us to move beyond the way things seem in introspection to the way things are. ${ }^{4}$

\footnotetext{
${ }^{3}$ This is standardly understood in terms of de re awareness. Eloise might still be aware that she is having an experience. See Tye (2009:5) and Tye (2014a: 40). For the various ways of formulating this portion of the transparency claim —-something we don't touch on here-see Gottlieb (2016).

${ }^{4}$ When we say that 'experience is transparent,' we are referring to the introspective claim. When we ask 'what follows from transparency' (or related questions), context will make clear whether we are asking what follows from the metaphysical claim or just the introspective claim.
} 
Michael Tye's $(2002,2009,2014)$ transparency theory is the most developed and influential in the literature. Tye's metaphysical claim is an externalist thesis about p-properties:

P-Externalism P-properties, if instantiated at all, are instantiated by objects in the subject's ambient environment; moreover, p-properties are frequently instantiated.

P-Externalism involves two claims. The first implies that our experiences never instantiate p-properties, and that in non-veridical experiences p-properties are uninstantiated. The second implies that most experiences are veridical on the supposition, given voice to by Harman, that p-properties seem to be instantiated by objects in one's environment.

P-Externalism is supposed to have stark implications for the nature of perceptual experience. It entails that both qualia realism and projectivism are false. ${ }^{5}$ And, according to Tye, we can use P-Externalism in an abductive inference to an externalist version of representationalism, on which p-properties are represented properties. ${ }^{6}$

Of course, there is plenty of action surrounding the introspective claim too, typically with respect to its purported universality (e.g. Block 1996; Kind 2003; Smith 2008). But here we just assume it, focusing on its implications once supplemented with an appropriate auxiliary claim. Also, when it is said that transparency tells us nothing much at all, the focus is on the introspective claim (e.g. Schroer 2007). We grant this; the introspective claim can be accommodated by just about any theory of perceptual experience (cf. Gupta 2012: 12; Frey 2013; Gow 2016). The auxiliary claim does the heavy lifting.

${ }^{5}$ Our focus is on literal projectivism, as opposed to figurative projectivism; on the former, colors are instantiated in the visual system, and in virtue of this instantiation objects look colored, while on the latter, colors are uninstantiated (Shoemaker 1994). For literal projectivism, see Boghossian \& Velleman (1989) and Averill (2005); for figurative projectivism, see Averill (1992); Wright (2003).

${ }^{6}$ Every use of 'representationalism', unless noted otherwise, should be understood as referring to externalist representationalism. P-Externalism embodies Tye's claim that " $[\mathrm{t}] \mathrm{he}$ phenomenal character of an experience...is out there in the world" (2009: 119). We are aware of p-properties. Thus P-Externalism also follows from Tye's (2014: 41) claim that "[t]he only features of which we are aware and to which we can attend are external features," and that, in non-veridical experience, "[t]he only features of which we are aware and to which we can attend are locally un-instantiated features of a sort that, if they belong to anything, belong to external particulars." For the claim 
We have three aims: one negative, one positive, and one meta-theoretical. Our negative aim is to scrutinize Tye's theory and show that it is flawed. Our positive aim is to develop a new transparency theory. Unlike Tye's theory, our theory is consistent with projectivism and qualia realism, and it provides no evidence for representationalism or naive realism. But it does tell us something about the nature of p-properties themselves. This is a feature, not a bug, and it bears on our metatheoretical thesis.

To see why, consider the criterion for a metaphysical claim in our above schema. It is broad. It speaks only of 'some disconnect' between p-properties and our experiences of them, leaving open the nature of that disconnect, and whether it reveals more about p-properties than it does about perceptual experiences. This is by design. Much attention to transparency in the literature has been due to the idea that transparency, or transparency theories, can tell us something important about the nature of perceptual experience. This is clearly Tye's motivation, and it evinces a certain meta-theoretical position, viz. that transparency is of interest because we can use it to sort through different candidate positions regarding what having a perceptual experience consists in. Tye is thus an optimist about the prospects of transparency being a game changer in this way.

We think that the optimistic position is misguided. Consider the following remarks from Alex Byrne and Heather Logue:

[T] he transparency of experience fits nicely with the view that in having an experience of, say, a tomato, although one may be in a position to learn something about the essence of the tomato, one is not a position to learn much of anything about the essence of the experience (2008: 82).

Byrne and Logue are (tacitly) advancing a modest meta-theoretical position. On this view, the lesson and interest of transparency concerns not the nature of perceptual experience, but the nature of the objects of experience-what our experiences

that P-Externalism is incompatible with qualia realism, see Tye (2014: 42-43). For the inference to representationalism as the best explanation of P-Externalism, see Tye (2002: 141). 
are $o f .{ }^{7}$ Note that there is a sense in which the modest position is far more modest than the optimistic position. For the latter does not say that we do not learn about the nature of the objects of experience from transparency. It just makes the additional claim that we learn about experiences themselves, either directly, or indirectly via what we learn about the objects of experience. The modest position only differs by denying that we learn anything of substance concerning the essence of perceptual experience.

Byrne and Logue also consider a skeptical meta-theoretical position:

Transparency goes naturally with modesty about experience-we know little of the nature of experiential episodes. What's more, it goes naturally with skepticism about experience-there are no experiential episodes to begin with (ibid: 83, our emphasis).

Here the lesson of transparency is that perceptual experiences don't exist. ${ }^{8}$

We won't go so far as to endorse the skeptical position. But we agree with Byrne and Logue that transparency "fits nicely" with the modest position; after all, the Harman-esque insight behind transparency is that we don't seem to be aware of our experiences anyway. (Eloise only experiences the tree.) So the modest position is prima facie plausible.

Our third aim, then, is to strengthen the case for the modest position. In broad strokes, our argument runs like this. If Tye's theory is unsuccessful-if arguably the most developed position on transparency and its implication fails to vindicate the optimistic position-and if our theory is successful, the modest position, while perhaps not fully vindicated, will be on surer footing. This is important, since it will have the effect of potentially re-directing efforts when thinking about transparency.

\footnotetext{
${ }^{7}$ On our usage, 'objects' of experience include objects proper, properties, and propertyinstances.

${ }^{8}$ This is skepticism about experiences qua particular mental events. As Byrne (2011: 64) notes, such skepticism allows that we can still truthfully say things like 'Going to Tahiti was a relaxing experience,' suitably paraphrased. See Speaks (2014) for a similar skeptical position based on transparency.
} 


\section{Tye's Transparency Theory}

Suppose you have a visual experience as of a red balloon. Your experience has a certain phenomenal character which is (chiefly) characterized by specific pproperties of shape (roundness) and color (redness). You are aware of these properties and they seem to be properties of the balloon, not properties of the very experience you are undergoing. Since you are inclined to take appearances at facevalue you conclude that the balloon is in fact round and red.

Generalizing from this description over any phenomenal property $\mathrm{F}$, any subject $S$, and any experience $E$, the introspective component of Tye's theory is this:

I-Claim When $\mathrm{S}$ is aware of $\mathrm{F}$ in virtue of having $\mathrm{E}$, (i-I) $\mathrm{F}$ will seem (to $\mathrm{S}$ ) to be a property of an object in Ss ambient external environment (including S's body), and (ii-I) neither F, nor any of the features of F, will seem to $\mathrm{S}$ to be a property of E itself. ${ }^{9}$

I-Claim holds for hallucinatory experiences, because, according to Tye (2002: 141; cf. 2014a), hallucination is a matter of standing in an awareness relation to uninstantiated p-properties. If $\mathrm{S}$ had a hallucinatory experience as of a red balloon, there would be no balloon to instantiate $\mathrm{F}$ (redness). Yet $\mathrm{F}$ will still seem to be to be property of the balloon (i-I), and F will not seem to $\mathrm{S}$ to be a property of her experience of the balloon (ii-I). ${ }^{10}$

Tye thinks that P-Externalism follows from I-Claim and his auxiliary claim. The main burden of this section is to scrutinize the inference from I-Claim to P-Externalism. This requires a close examination of Tye's auxiliary claim. But

\footnotetext{
${ }^{9}$ Two points. First, we stress that I-Claim is Tye's introspective claim. This is not to say that we think I-Claim is implausible; it is plausible. But the form and generality of the introspective claim is certainly not entirely stable throughout the literature on transparency. For other versions of the introspective claim, compare Kind (2003), Stoljar (2004), Molyneux (2009), and Kennedy (2009). Second, I-Claim can be formulated without committing to the existence of experiences-and so consistent with the skeptical meta-theoretical position - by simply say that the only thing F seems to be a property of are objects in S's environment.

${ }^{10} \mathrm{We}$ assume, with Tye (2014ab), that one is aware of p-properties in hallucination. For a contrary view, see Pautz (2007).
} 
before doing so, we'll explore the relationship between P-Externalism and Tye's optimistic meta-theoretical position.

\subsection{P-Externalism and the Optimistic Position}

P-Externalism is, in the first instance, a claim about the objects of experienceour experiences are, amongst other things, of p-properties. P-Externalism implies that qualia realism is false. That's no doubt an important result, but to what extent would this vindicate the optimistic position? One might suggest that it vindicates the position insofar as we would now know what experiences are not: they are not mental events with intrinsic non-intentional properties that type them phenomenologically. Yet this advance is, in another sense, not really an advance at all for the optimist. For notice that, in establishing the falsity of qualia realism, we have removed one reason for thinking there are experiences to begin with-viz. that they are those things that instantiate the p-properties we are aware of when we consciously see, hear, smell and feel. The upshot is that, when transparency tells us what an experience is not, not what experiences are, this won't vindicate the optimistic position if, in the process, we are given less reason to believe in experiences anyway.

Now if P-Externalism gave us evidence for representationalism, we will have gone some way towards vindicating the optimist. P-Externalism is consistent with representationalism, and - as noted — the argument from P-Externalism to representationalism is abductive, meant to rule against other P-Externalism-consistent views like naive realism. There is an oddity here, though. If P-Externalism is true, p-properties can be represented unconsciously. This is because, by P-Externalism, p-properties are just properties of objects around us. ${ }^{11}$ So even if by abduction PExternalism implied that experiences are representations, we wouldn't know what it is that makes these representations experiences. We wouldn't know this because we would not have singled out anything that experiences uniquely represent. Thus

\footnotetext{
${ }^{11}$ Unless you don't believe in unconscious perception. This route will be appealing to very few (if any) representationalists, and certainly not to Tye.
} 
we would be no closer to ascertaining the difference between unconscious perception and conscious perceptual experience. Of course, this point is not lost on Tye (2000; 2014b), which is why he appeals to a functional role property-viz. being poised to impact the right cognitive centers - to distinguish conscious and unconscious perception. But Tye did not arrive at this conclusion from an abductive argument from P-Externalism for representationalism.

We don't downplay the importance of P-Externalism. If it turned out that pproperties were just properties of objects around us, then perhaps they would just be ordinary physical properties, which would thus make naturalizing the mind easier. ${ }^{12}$ And it might be that these properties play a role in the identity conditions for perceptual experience, as Tye would have it. Yet this still does little to tell us what experiences themselves actually are, even assuming they are representations. This is because the properties that individuate experiences phenomenologically are not properties of the experience, and not everything that represents them is an experience. So our general point is that the connection between P-Externalism and the optimistic meta-theoretical position is tenuous at best. What we argue for next, however, is that Tye's case for P-Externalism is quite weak anyway.

\subsection{From I-Claim to P-Externalism}

In moving from I-Claim to P-Externalism, Tye says this:

To suppose that the qualities of which perceivers are directly aware in undergoing ordinary everyday visual experiences are really qualities of the experience would be to convict such experiences of massive error. That is just not credible. It seems totally implausible to hold that visual experience is systematically misleading in this way. Accordingly, unless it can be shown that serious trouble ensues, the qualities

\footnotetext{
${ }^{12}$ Tye wants to say that p-properties are physical properties, but strictly speaking it's not clear that this follows from P-Externalism. Presumably, for P-Externalism to show that p-properties are physical properties it would have to follow from P-Externalism alone that p-properties enter laws or causal interactions at the level of physics.
} 
of which you are directly aware in focusing on the scene before your eyes and how things look are not qualities of your visual experience (2002: 139).

Tye's auxiliary claim can thus be stated as follows:

Veridicality Perpetual experience is not systematically misleading; generally, if in virtue of having $\mathrm{E}$, $\mathrm{x}$ seems $\mathrm{F}$ to $\mathrm{S}$, then $\mathrm{x}$ is $\mathrm{F}$.

The question we are entertaining, then, is this: how exactly does Tye employ Veridicality to bridge I-Claim and P-Externalism? We will look at this from two angles; first, a deductive one, and second, an abductive one. ${ }^{13}$

\subsubsection{The Deductive Reading}

Bernard Molyneux (2009) treats Tye's inference deductively. But as he points out, the second conjunct (ii-I) of I-Claim - that F does not seem to be a property of $\mathrm{E}$ - is really a fifth wheel. It's a claim about what experiences doesn't tell us. It doesn't say that we are aware of $\mathrm{F}$ as not being a property of E (ibid: 120). So it is the first conjunct (i-I) of I-Claim that is doing the work. Following Molyneux (ibid) once more, here is a deductive reading of Tye's argument:

T1 When $S$ has a perceptual experience of F, F seems to be (to $S$ ) a property of an object in S's environment. [(i-I)]

T2 Perceptual experience is not misleading in this respect.

$\therefore \quad$ F is a property of an object in S's environment.

T3 If $\mathrm{F}$ is a property of an object in S's environment, then $\mathrm{F}$ is not a property of $\mathrm{E}$.

$\therefore \quad$ F is not a property of $\mathrm{E}$.

\footnotetext{
${ }^{13}$ We thank an anonymous referee for pushing us to consider the abductive version.
} 
The argument has three premises: T1 1 , T2D, and T3 ${ }_{\mathrm{D}}$. We are granting T1 $1_{\mathrm{D}}$ since we are granting I-Claim. The naive realist would likely reject T3 , insisting that there is a sense in which external objects and property-instances partly constitute our experiences (cf. Kennedy 2009). We'll bracket that though, and focus on T2D.

The first thing to note is that T2 ${ }_{\mathrm{D}}$ is not actually Veridicality. This is intentional. Veridicality is not strong enough to do the work Tye wants, since it wont allow him to infer that $\mathrm{F}$ is a property of an object in S's environment from T1. This is because Veridicality only says that experience is not generally misleading when it attributes $\mathrm{F}$ to $\mathrm{x}$. It is consistent with this that there are at least some F's that are falsely attributed to $x$. So T2 $2_{D}$ seems better.

But now there is another problem, for P-Externalism is supposed to be a fully general thesis, i.e. one that covers both veridical and non-veridical experiences (Tye 2014a: 41). Again: P-Externalism says that if $\mathrm{F}$ is instantiated, it is instantiated in some external object. In illusory and hallucinatory cases the antecedent of this conditional is (plausibly) assumed to be false. The metaphysical lesson of I-Claim is not supposed to be a restricted one, such that when $\mathrm{E}$ is hallucinatory, the $F$ we are aware of in virtue of being in $E$ is also instantiated by $E$. In such cases, F is simply uninstantiated. Saying otherwise cuts against everything Tye wants out of a transparency theory.

Here T1D and T2D imply that $\mathrm{F}$ is a property of an object in S's environment. Thus the following $\mathrm{T} 1_{\mathrm{D}}-\mathrm{T} 2_{\mathrm{D}}$ conditional holds: if $\mathrm{S}$ has a perceptual experience of $\mathrm{F}$, then $\mathrm{F}$ is instantiated in some external object. The problem is that, within the contextual assumptions of Tye's argument, this $\mathrm{T} 1_{\mathrm{D}}-\mathrm{T} 2_{\mathrm{D}}$ conditional is false for illusion and hallucination because the generality of P-Externalism depends on the assumption that in the case of illusion and hallucination $\mathrm{F}$ is uninstantiated. In illusions and hallucinations $\mathrm{S}$ has a perceptual experience of $\mathrm{F}$ (the antecedent of the $\mathrm{T} 1_{\mathrm{D}}-\mathrm{T} 2_{\mathrm{D}}$ conditional is true), but $\mathrm{F}$ is not a property of an object in S's environment (the consequent of the $\mathrm{T} 1_{\mathrm{D}}-\mathrm{T} 2_{\mathrm{D}}$ conditional is false). Since the argument for the $\mathrm{T} 1_{\mathrm{D}}-\mathrm{T} \mathrm{D}_{\mathrm{D}}$ conditional from the $\mathrm{T} 1_{\mathrm{D}}$ and $\mathrm{T} \mathrm{D}_{\mathrm{D}}$ premises is valid at least one of these premises is false; clearly that premise is $\mathrm{T} 2{ }_{\mathrm{D}}$. 
This point shows that on Tye's theory the generality of P-Externalism is inconsistent with the way P-Externalism is supported. The upshot is that, on the assumption that the metaphysical lesson is to hold in all cases-that is, in both veridical and non-veridical experience-Veridicality cannot stand alone as Tye's sole auxiliary thesis. But instead of seeing how Veridicality could be supplemented in a deductive argument for P-Externalism, it will be more instructive to see how Veridicality works in an abductive argument for P-Externalism.

\subsubsection{The Abductive Reading}

The abductive version of Tye's argument presumably goes something like this:

T1 $1_{A}$ p-properties seem to be properties of external objects, and they dont seem to be properties of our experience.

T2 $\mathbf{A}_{\mathrm{A}}$ Perpetual experience is not systematically misleading.

T3 ${ }_{\mathrm{A}}$ If true, P-Externalism would offer a better explanation of $\mathrm{T} 1_{\mathrm{A}}$ and $\mathrm{T} 2{ }_{\mathrm{A}}$ and then competing alternatives.

$\therefore \quad$ P-Externalism is true.

$\mathrm{T} 1_{\mathrm{A}}$ approximates I-Claim; $\mathrm{T} 2{ }_{\mathrm{A}}$ approximates Veridicality. But here Veridicality is not really functioning as a premise - a claim that needs to be independently argued for. Instead, it is a functioning a something like a desideratum, or a fixed data point that we should all assume as a given. Tye seems to have this in mind when he says that denying $\mathrm{T} 2{ }_{\mathrm{A}}$ is "just not credible" (2002: 139) and "seems totally implausible" (2000: 46); beyond this, Tye never argues for Veridicality. What's being advanced in the abductive argument from I-Claim to P-Externalism, then, is that P-Externalism is the best explanation of not just I-Claim, but Veridicality too. Once we know that p-properties are properties of external objects in veridical experience (by I-Claim and Veridicality), the simplest option is to let them go uninstantiated in non-veridical experience. This is better (because simpler) than 
ending up with a dis-unified approach to perceptual experience on which veridical and non-veridical experiences are different in kind.

To some audiences, this argument will be compelling. Yet it carries little force against the opponent of P-Externalism. Both the qualia realist and projectivist reject P-Externalism. But they also do, or at least can, endorse I-Claim. Projectivists clearly do, and qualia realists can; as Gow (2016) points out, while qualia realist have rejected I-Claim, there is certainly nothing about the position as such that forces their hand. And this is good, since I-Claim, or something near enough, is plausible.

Now if you accept I-Claim, but reject P-Externalism, then you will have to reject $\mathrm{T} 2{ }_{\mathrm{A}}$, i.e. Veridicality. And this, of course, is exactly what the projectivist does. She does this not because she thinks Veridicality is absurd-it isn't—but because in the case of phenomenal colors (a kind of p-property) specifically, we are dealing with something that (according to her lights) cannot be instantiated by ordinary physical objects. So, not only is Veridicality not a fixed data point for all parties, it is something that opponents of P-Externalism will naturally afford far less weight than Tye. It is thus ineffective to take something that all parties do or can agree to (I-Claim) and then supplement that with an assumption or desiderata that your opponents do not or need not agree with (Veridicality), to then infer a thesis (P-Externalism) that entails the falsity your opponent's position.

For a related reason, the appeal to simplicity or parsimony doesn't help either since such considerations are germane only after it is agreed that all other things are equal. If all parties concurred on the truth of Veridicality, then any theory which countenanced p-properties as being instantiated by non-veridical experiences would certainly count as less parsimonious, and for that reason have a mark against it. Yet the whole point is that everyone does not agree on this much. Anyone that ascribes to (say) projectivism will already be committed to rejecting Veridicality if, as we are assuming, they ascribe to I-Claim.

In sum, Tye's argument, when construed in abductive terms, won't convince anyone who isn't already committed to P-Externalism. Tye's abductive argument 
is thus unsuccessful.

\section{A New Transparency Theory}

Thus far, we have shown that the case for P-Externalism fails. We have also shown that even if P-Externalism were true, it is limited in the extent to which it can vindicate the optimistic meta-theoretical position. In this section, we set out our competing transparency theory. We start in Sect. 3.1 by setting out our metaphysical claim, and comparing it to Tyes P-Externalism. In Sect. 3.2 we introduce and defend our auxiliary claim. Then in Sect. 3.3, we employ our auxiliary claim to derive our metaphysical claim from I-Claim. Finally, Sect. 3.4 sets out the implications of our theory. Here the focus is on the objects of experience, not experiences themselves. On this score, our ambitions are limited. But, when taken together with the failure of Tye's theory to vindicate the optimistic meta-theoretical position, it provides evidence for the modest position.

Before we jump in, a terminological note. Phenomenal relations have been implicit in our discussion, since relational p-properties are p-properties. However, in this section we need to explicitly refer to phenomenal relations. We could do this by referring to them as relational p-properties, but it is less awkward to refer to them more simply as phenomenal relations, or p-relations. And we introduce 'p-features' as a catchall term, covering both p-properties (i.e. non-relational pproperties) and p-relations (i.e. relational p-properties).

\subsection{Our Introspective and Metaphysical Claims}

Our introspective claim is the same as Tye's, viz. I-Claim. This is critical, for we are starting from the same introspective evidence. The question for all parties is what we should conclude on the basis of this evidence.

Here is our metaphysical claim:

P-Essentialism For any p-feature $\mathrm{F}$ and any perceptual experience $\mathrm{E}$ of $\mathrm{F}$, 
no p-relation holds between $\mathrm{F}$ and $\mathrm{E}$ that is essential to $\mathrm{F}$.

P-Essentialism fits the metaphysical component of our schema. For if we deny PEssentialism - if we say that there is a p-relation between $\mathrm{F}$ and $\mathrm{E}$ that is essential to $\mathrm{F}$-then there is a significant metaphysical connection between p-properties and our experience of them.

Two points of comparison between P-Essentialism and P-Externalism: First, P-Externalism is about where p-features would be instantiated, if they were instantiated, and adds that $\mathrm{p}$-features are often instantiated. P-Essentialism makes no such instantiation claim. However, we have seen that Tye's use of Veridicality to obtain this instantiation claim is dialectically illicit. So Tye is not entitled to conclude that $\mathrm{p}$-features are properties of the objects around us, and neither are we from our transparency theory alone. Yet it's worth noting that nothing in our transparency theory is at odds with Veridicality. So our theory plus Veridicality implies that $\mathrm{p}$-features are properties of the objects around us.

Second, both P-Externalism and P-Essentialism make claims about the nature of p-features, and so are in line with the modest position: that the F's are properties of ordinary objects (on the former), and that there is no p-relation between any $\mathrm{F}$ and any $\mathrm{E}$ that is essential to $\mathrm{F}$ (on the latter). We will also show, in section 3.4.1, that P-Essentialism plus a reasonable assumption implies that there is no relation between $\mathrm{F}$ and $\mathrm{E}$ that is essential to $\mathrm{F}$; that is, that $\mathrm{p}$-features are mindindependent. P-Externalism, by contrast, is consistent with phenomenalism about p-features, since it is consistent with the claim that $\mathrm{p}$-features are properties of objects around us yet are mind-dependent (cf. Pelczar 2015). Granted, this difference is likely just a technicality; we find phenomenalism implausible, and we venture that Tye does as well. Still, note that, in saying that $\mathrm{p}$-features are mindindependent, P-Essentialism arguably gives one as much of a metaphysical punch as P-Externalism. 


\subsection{Our Auxiliary Claim: Essential Features}

Our auxiliary claim, and our argument for P-Essentialism, rests on our answer to this basic question: What features of a p-feature must one be conscious of in order to experience the p-feature? We begin our answer with two assumptions about $\mathrm{p}$-features, which we believe are uncontroversial.

The Type Assumption: p-features type perceptual experiences by what it is like to have them. What it is like to have an experience-the totality of what it is like-is given by that experience's phenomenal character. P-features characterize an aspect of that total phenomenal character by making a contributive phenomenal difference to what it is like for the subject. My experience of a red square is in some way phenomenally similar to my experience of a green square. But they differ in their total phenomenal characters because some of the p-features (viz. p-colors) that comprise their phenomenal characters are different-p-redness in one case, p-greenness in the other. ${ }^{14}$ Types, not tokens, type experiences; that is, p-feature types type experiences by what it is like to have them. A p-feature token is an instantiated token that, experienced under normal conditions, is experienced as an instance of a phenomenal type.

The Consciousness Assumption: we are conscious of p-features. It is unintelligible to claim that $\mathrm{F}$ types my experience by what it is like to have it, yet insist that $\mathrm{I}$ am in no way conscious of $\mathrm{F}$. The difference between my experience of a red square and my experience of a green square is the presence and absence of p-greenness and p-redness. I might not have to be aware that it is the presence and absence of these p-properties that make my experiences differ phenomenologically, but I do have to be conscious of the p-features in virtue of which there is this difference.

But how exactly are we conscious of p-feature types? Suppose that subject $\mathrm{S}$

\footnotetext{
${ }^{14}$ Many things can make a difference to experience without making a difference to an experiences' phenomenal character. The cosmological constant makes such a difference; if the constant were different, there wouldn't be any experiences. But there is no element of phenomenal character that corresponds to the cosmological constant. That's why the cosmological constant isn't a p-feature. It is just an enabling condition for there being experiences at all.
} 
is looking at object $\mathrm{x}$. And suppose that $\mathrm{S}$ is conscious of $\mathrm{x}$ as an $\mathrm{F}$, then $\mathrm{S}$ is conscious of $x$ and conscious of $F$. Suppose $x$ is a cow. $S$ might be conscious of a cow as a cow; or $\mathrm{S}$ might be conscious of a cow as a horse. If $\mathrm{S}$ is conscious of a cow as a cow, then $\mathrm{S}$ is not only conscious of the physical cow, she is also conscious of the property type - the cow type - that she attributed to the cow. (You cannot be conscious of representing an object as having a property without being conscious of the attributed property.) If $S$ is conscious of a cow as a horse, then $S$ is not only conscious of the cow (a token) but she is also conscious of the property type - the horse type-she attributed to the cow. So if F is a p-feature that types $\mathrm{S}$ 's experience of $\mathrm{x}$ then $\mathrm{S}$ is conscious of the $\mathrm{F}$ as a p-feature type. ${ }^{15}$

With these assumptions in place, as a first step toward answering the basic question consider now the following two claims. For a p-feature $\mathrm{F}$ to type experience $\mathrm{E}, \mathrm{F}$ must type $\mathrm{E}$ with respect to all of F's essential p-features; for otherwise it would not be $\mathrm{F}$ that was typing $\mathrm{E}$. And for a subject to be conscious of $\mathrm{F}$ the subject must be conscious of all of the essential p-features of $F$; for otherwise the subject would not be conscious of $\mathrm{F}$.

These claims can be illustrated in multiple ways. First, consider the experience of seeing a red patch. A subject $S$ has a visual experience $E$ of a red patch $R$. $R$ has a specific shade. Let it be scarlet. We will assume that the scarletness of $R$ types Ss experience $\mathrm{E}$ by what it is like to have it and that $\mathrm{S}$ is conscious of the scarletness of R. So scarletness is a p-property. Scarletness has a specific hue $(h)$, saturation $(s)$ and lightness $(l)$. The $h, s$ and $l$ properties of scarletness identify its location in a color space that lays out all the color shades of non-radiant objects in the dimensions of hue, saturation and lightness. So $h, s$ and $l$ are what make scarletness different from all other colors. Hence these properties- $h, s$ and $l-$

\footnotetext{
${ }^{15}$ Here we think of tokens as the stimuli that can cause the visual system of a subject looking at a token to type it. This is expressed in the $\mathrm{S}$-is-conscious-of- $\mathrm{X}-\mathrm{as}-\mathrm{an}-\mathrm{F}$ relation, where $\mathrm{x}$ is the token and $\mathrm{F}$ is the type. The subject is conscious of both the type and the token. What we are calling typing psychologist call categorizing. Understanding vision this way explains illusionsthe subject mistypes the token; and the duck-rabbit - the same token is typed in two different ways; and color agnosia-the color agnosic cannot type tokens by color. The agnosic does not experience the type; the hallucinator does not experience the token.
} 
are essential to scarletness. To experience scarletness, $\mathrm{S}$ must be conscious of $h$, $s$ and $l$. These properties type S's experience phenomenologically, because if any one of these properties were to change $\mathrm{S}$ would have a different experience with a different phenomenal character. Scarletness would not phenomenologically type $\mathrm{E}$ if $h, s$ and $l$ did not phenomenologically type E. The upshot is that $h, s$ and $l$ are themselves p-properties-when $\mathrm{S}$ experiences scarletness, $\mathrm{S}$ is conscious of them and there is something that it is like to experience them-and they are essential properties of the p-property scarletness. They all make a contributive phenomenal difference.

To make this point sharper, consider a related case. Suppose that a distinct subject $\mathrm{S}^{*}$ has a distinct visual experience $\mathrm{E}^{*}$ of the same red patch $\mathrm{R}$. Yet $\mathrm{S}^{*}$ only glances at $R$. She sees that it is red, but notices nothing more; that is, when $\mathrm{S}^{*}$ glances at $\mathrm{R}$ she is aware of its redness, its hue, but is not aware of whether the color of $\mathrm{R}$ is crimson, scarlet or some other shade of red. What it is like for $\mathrm{S}^{*}$ to undergo $\mathrm{E}^{*}$ is thus different from what it is like for $\mathrm{S}$ to undergo $\mathrm{E}$. They have different phenomenal characters. But that means there must be a difference in $\mathrm{p}$ features. The difference is between experiencing scarletness, as $\mathrm{S}$ does, and just experiencing redness as $\mathrm{S}^{*}$ does. True, there is likely some sense of experience in which $\mathrm{S}^{*}$ has an experience of scarletness. Yet $\mathrm{S}^{*}$ does not, if you like, experience scarletness as a p-property, because in whatever sense $\mathrm{S}^{*}$ experiences scarletness, it is not in a manner such that scarletness makes a contributive difference to the experience's phenomenal character. ${ }^{16}$ This is because, having only glanced at that the patch, $S^{*}$ is not conscious of all the p-properties that are essential to scarletness. Only when $\mathrm{S}$ is conscious of all the $\mathrm{p}$ - properties essential to scarletness will scarletness itself make a contributive difference to the phenomenal character of $\mathrm{E}^{*}$. Only then will scarletness be a p-property—be experienced as a p-property. ${ }^{17}$

\footnotetext{
${ }^{16}$ When we say 'as a p-feature,' the 'as' (in this case only) is not meant to signify conceptpossession. $S^{*}$ need not possess the concept PHENOMENAL FEATURE. Our point is simply that in whatever sense $\mathrm{S}^{*}$ experiences $\mathrm{F}$, it is not in a manner such that $\mathrm{F}$ makes a contributive difference to the experience's phenomenal character. That's the sense in which $\mathrm{S}$ does not experience $\mathrm{F}$ as a p-feature.

${ }^{17}$ For some purposes it may be helpful to think of redness as a determinable (a hue) whose
} 
The takeaway is that to experience scarletness as a p-property one must experience all the p-properties of scarletness that are essential to scarletness. Of course, it does not follow from this that one is conscious of all the (non-phenomena) essential features of scarletness, or conscious of the essential p-features of scarletness as essential features. But generalizing from this case about p-properties to p-features, the following principle emerges: If $F$ is a p-feature, then $S$ must be conscious of all the p-features essential to $F$, but need not be conscious of F's essential $\mathrm{p}$-features as essential $\mathrm{p}$-features. This principle is our answer to the question we started with: What features of a p-feature must one be conscious of in order to experience the $\mathrm{p}$-feature?

We can make the same point with p-shapes. Let triangular-shapes be the shapes of closed three-sided figures, and let angular-shapes be the shapes formed when two rays have the same end point, but do not lie on the same line. An essential p-feature of any triangular-shape is that it has some-interior-angle-shapes. ${ }^{18}$ So, again, our claim is that if the triangular-shape is a p-property-if the triangularshape itself types an experience by what it is like to have it - then $\mathrm{S}$ must be conscious of some-interior-angle-shapes as a p-feature of the triangular-shape. It is this p-feature that makes 'triangular phenomenology' what it is. If instead the triangle was so small that it just looked like a dot on a piece of paper, S could, in some sense, experience the triangle, but the triangular-shape would not itself be a p-property. It would not be experienced as a p-property. And this is because the triangle was too small for $\mathrm{S}$ to be conscious of its interior-angle-shapes, i.e. a p-feature essential to p-triangularity. As before, $S$ need not be conscious of the interior angle-shapes as an essential feature of the triangular-shape. And S need not be conscious of all the shape's essential features. An essential feature of a

determinates include scarlet and crimson (they have the same hue). In this case $\mathrm{S}$ experiences the determinate scarletness (its $h, s$ and $l$ ) and $\mathrm{S}^{*}$ experiences the determinable redness $(h)$. This way of thinking about the experiences of $S$ and $S^{*}$ makes no difference to our argument for the claim that these experiences are different experiences of different p-properties-scarletness for $\mathrm{S}$, redness for $\mathrm{S}^{*}$ - and so have different phenomenal characters.

${ }^{18}$ Of course, the triangular-shape has three interior angle-shapes. However, we just used 'some interior angle-shapes' because it is questionable that three-ness is phenomenal. 
(Euclidian) triangle is that its interior angles sum to 180 degrees. But this is not a p-feature of a triangular-shape. We can have 'triangle experiences' without being conscious of this. We cannot, however, have triangle experiences without being conscious of all the $\mathrm{p}$-features essential to the triangular-shape.

One final example, this time dealing only with p-relations. Let $\mathrm{L}$ be the $\mathrm{p}$ relation one-circle-surrounds-another and let $\mathrm{B}$ be the p-relation one-circle-isbigger-than-the-other. Now suppose I have a 'concentric circle experience'- the kind of experience I have when I direct my visual focus to two concentric circles on a piece of paper. B is an essential p-feature of L, although B can hold between two circles that are not concentric. So $L$ is an essential p-feature of my concentric circle experience and $B$ is a constitutive p-feature of $L$, which makes $\mathrm{B}$ a constitutive $\mathrm{p}$-feature of my experience. Thus, for $\mathrm{S}$ to have concentric circle experience-for $\mathrm{S}$ to have an experience that it is typed by the p-relation $\mathrm{L}-\mathrm{S}$ must be conscious of B.

Given these considerations, the following holds:

Essential Features Necessarily, for any p-feature F, if subject $S$ is conscious of $F$, then $S$ is conscious of (at least) all of the p-features essential to $F\left(F^{\prime}, F^{\prime}, F^{\prime \prime}\right.$ '...) and of all their p-features essential to them (that is, the p-features essential to F', F', F'”...).

Essential Features is our auxiliary claim. It does not entail that $\mathrm{S}$ need be conscious of any essential p-feature of a p-feature as an essential p-feature of that p-feature. We have not provided a full-dress argument for this claim. But we do take the above illustrations to show its attractiveness given The Type and Consciousness Assumptions.

\subsection{The Argument for P-Essentialism}

The derivation of P-Essentialism begins by assuming the antecedent of both IClaim and Essential Features: 
E1 S is perceptually conscious of $\mathrm{F}$ in virtue of having $\mathrm{E}$.

We then get:

E2 S is conscious of (at least) all of the p-features essential to $F\left(F^{\prime}, F^{\prime}, F^{\prime \prime}\right.$ '...) and of all their $\mathrm{p}$-features essential to them (that is, the p-features essential to $\left.F^{\prime}, F^{\prime}, F^{\prime \prime}, . ..\right)$.

E3 None of the p-features essential to $\mathrm{F}$ seem to $\mathrm{S}$ to be a feature of $\mathrm{E}$ itself.

Here E2 is the consequent of Essential Features and E3 is the second conjunction in the consequent of I-Claim. ${ }^{19}$ We then proceed via reductio:

E4 There is a p-relation $\mathrm{R}$ that holds between $\mathrm{F}$ and $\mathrm{E}$ that is essential to $\mathrm{F}$. [Assume for reductio]

E5 So, $\mathrm{S}$ is conscious of $\mathrm{R}$. [first conjunct of 2, 4]

E6 An essential p-feature of $\mathrm{R}$ is that it is a p-relation between $\mathrm{F}$ and $\mathrm{E}$ that is essential to $\mathrm{F}$.

E7 So, $\mathrm{S}$ is conscious of R's being a relation between $\mathrm{F}$ and $\mathrm{E}$. [second conjunct of $2,5,6]$

E8 If none of the p-features essential to $F$ seem to $S$ to be a feature of $E$ itself, then $\mathrm{S}$ is not conscious of R's being a relation between $\mathrm{F}$ and $\mathrm{E}$.

E9 So, $\mathrm{S}$ is not conscious of R's being a relation between $\mathrm{F}$ and E. [3,8]

$\mathbf{E 1 0} \perp[7,9]$

\footnotetext{
${ }^{19} \mathrm{E} 3$ is not quite (ii-I) of I-Claim, since E3 has 'essential' where (ii-I) does not. This addition makes our derivation easier, but note that such a move is not elicit in this context; after all, Tye would grant E3; if F does not seem to a subject $S$ to be a feature of one's experience E, then surely none of the p-features essential to $\mathrm{F}$ will seem to $\mathrm{S}$ to be a feature of E. Notice also that the first conjunct of I-Claim (i-I) does not play a role in our derivation of P-Essentialism. But as we saw, the second conjunct (ii-I) does not play a role in Tye's argument for P-Externalism.
} 
We get a contradiction on E10 from E7 and E9. Since E4 is our premise for reductio, it follows that there is no p-relation $\mathrm{R}$ that holds between $\mathrm{F}$ and $\mathrm{E}$ that is essential to F. In other words, we get P-Essentialism.

The argument is valid. The question is whether it is sound. In the present context this turns on whether E6 and E8 is true.

On E6: note to begin with, that our argument is a general one that applies to all perceptual experiences involving F's and E's. So, in E4, R is an instance of a relation $\mathrm{R}$ that is to be understood as a p-relation that holds for all visual experiences involving F's and E's that are essential to F's. Hence these features are essential to R, as E6 says.

On E8: the way something seems - in the phenomenal sense of 'seems' - is a matter of the property types we attribute to that thing. By the antecedent of E8, neither F, nor any of the p-features essential to $F$, will seem to $S$ to be a feature of $\mathrm{E}$. Thus if ' $\mathrm{F}$ ' picked out $\mathrm{p}$-red, $\mathrm{S}$ would not experience $\mathrm{E}$ itself as being of the p-red type. Now $\mathrm{R}$ is a p-relation (a kind of $\mathrm{p}$-feature) between $\mathrm{F}$ and $\mathrm{E}$ that is essential to $F$. $S$ could be conscious of $R$ as being something other than a relation between $\mathrm{F}$ and $\mathrm{E}$, much in the way one could be conscious of a cow as being something other than a cow (e.g. as a horse). In such a case $\mathrm{R}$ might not seem to be a feature of $\mathrm{E}$. But suppose the consequent of $\mathrm{E} 8$ were false; suppose $\mathrm{S}$ were conscious of R's being a relation between $F$ and $E$. Then $R$ would seem to $S$ to be a relation between $F$ and $E$, and so a (relational) feature of $E$. This is because $S$ would be attributing to $\mathrm{R}$ a relational property (a property of a property); namely, the property of being a relation (between $\mathrm{F}$ and $\mathrm{E}$ ). But that's just what it means for S to be conscious of R's being a relation. Hence, by contraposition, E8 is true.

At full measure, then, our transparency theory is the conjunction of I-Claim (the introspective claim), P-Essentialism (our metaphysical claim), and Essential Features (our auxiliary claim). 


\subsection{Further Implications}

\subsubsection{For the Mind-Independence of P-Features}

Here's a question: what is it about the world that makes P-Essentialism true? The cleanest answer is this:

No-Relation For any p-feature $\mathrm{F}$ and any perceptual experience $\mathrm{E}$ of $\mathrm{F}$, no relation holds between $\mathrm{F}$ and $\mathrm{E}$ that is essential to $\mathrm{F}$.

From No-Relation it follows that p-features-be they p-colors, p-shapes, etc.are mind-independent. The reason is simple: for a p-feature (an F) to be mindindependent just is a matter of there being no relation between the experience of the $\mathrm{p}$-feature $(\mathrm{E})$ and the $\mathrm{p}$-feature itself, that is essential to the p-feature. ${ }^{20}$

If there is a challenge to No-Relation, it comes from relational accounts of color. Relational accounts hold that there is a connection between the way colors look and the way colors are. So it might be thought that on relational accounts of color No-Relation would be false. To see why this is not the case, let $\mathrm{S}$ be a subject, or a set of subjects, and let $\mathrm{C}$ be a circumstance of some kind. Relational accounts of color typically hold something like the following:

$$
\mathrm{x} \text { is red-for-S-in-C iff } \mathrm{x} \text { is disposed to look red-for-S-in-C. }{ }^{21}
$$

Suppose that redness entered the triadic relation red-for-S-in-C as a monadic property; that is, redness simply fills one term in a triadic relation. In this case the relational account of color would not capture all there is to color. Indeed the monadic property would seem to be the metaphysically important color property. Hence in (1) it is redness itself that is triadic. So (1) is not about p-redness, which is

\footnotetext{
${ }^{20}$ Both Tye's theory and our theory make assumptions about the way experience is related to the world: for Tye, Veridicality; for us, No-Relation. These claims are importantly different. Veridicality concerns the accuracy of perceptual attributives of the form ' $x$ seems F.' No-Relation, by contrast, explains the non-existence of one type of relation between $\mathrm{F}$ and $\mathrm{E}$ (viz. p-relations) by appeal to the non-existence of relations simpliciter between F and E. Perhaps Tye's assumption says more about the world, but as we saw this was his theory's undoing.

${ }^{21}$ See McGinn (1983: 6), Johnston (1992: 248), and Cohen (2011: 182).
} 
a monadic property, but about relational-redness. As such (1) is consistent with No-Relation.

In addition, as we will show next, No-Relation faces no indirect challenge by being inconsistent with a major theory of perception. Given this lack of argument against No-Relation, we assume that abductive grounds-namely, No-Relation explains why P-Essentialism is true-suffices to show that No-Relation follows from P-Essentialism. And in this way, the mind-independence of p-features also follows from P-Essentialism.

\subsubsection{For Perceptual Experience}

P-Essentialism is consistent with representationalism. Representationalism does not imply that there is a p-relation between F and $\mathrm{E}$ that is essential to F. Nor does naive realism imply that there is a p-relation between $\mathrm{F}$ and $\mathrm{E}$ that is essential to $\mathrm{F}$. In addition, both views are consistent with the best explanation for P-Essentialism being that there is no relation between $\mathrm{F}$ and $\mathrm{E}$ that is essential to $\mathrm{F}$. So representationalism and nave realism are consistent with No-Relation too.

What about qualia realism and projectivism? On literal projectivism: the literal projectivist will maintain that seeing something as p-red (or any other p-color) necessarily involves p-redness being instantiated in the subject's visual system. So it might be an essential feature of an experience that it instantiates p-redness, when the subject sees something as p-red. So in this case F may have an essential relation, the instantiation relation, to $\mathrm{E}$. But this is not to claim that it is essential to p-redness that it be instantiated in a visual system; $\mathrm{E}$ is not essentially related to F. Consider the thesis that granite instantiates p-redness, although we do not perceive this property of granite and scientists have not discovered this property to be in granite. Projectivism does not imply that this thesis is false because granite is not part of a visual system; that is, as far as literal projectivism is concerned predness could be instantiated in granite. Hence, on a literal projectivist account of color it is a contingent feature of p-redness that it is instantiated in some visual systems. As such, in this case it is a contingent feature of $F$ that it is instantiated 
in a visual system. So, projectivism is compatible with both P-Essentialism and No-Relation: projectivism does not require that there is a relation, phenomenal or otherwise, between $\mathrm{F}$ and $\mathrm{E}$ that is essential to $\mathrm{F}$.

Although qualia realism is rarely (if ever) fully developed in positive terms, the basic idea is simple enough: perceptual experiences instantiate intrinsic, normatively inert, introspectively accessible properties called qualia. And the set of qualia an experience instantiates constitutes that experience's phenomenal character (cf. Speaks 2014). So qualia play the role of p-features. As such, qualia realism can plausibly be treated like projectivism; although it is essential to my having a reddish experience that it instantiates a certain quale $Q$, it is not essential to $Q$ that it be instantiated by my experience. So, qualia realism is compatible with No-Relation, and a fortiori P-Essentialism.

That P-Essentialism is consistent, but does not entail, virtually every live theory of perceptual experience, or some kinds of perceptual experience, tells against the optimistic meta-theoretical position. ${ }^{22}$ We cannot look to transparency as a means to finding out which of the various accounts of perceptual experience is correct.

\subsubsection{For Revelation}

A final point. Bertrand Russell, Mark Johnston and Galen Strawson all examine something like the following epistemic claim about color: by simply having an experience of color, one is in a position to know the essential nature of (that) color. This, roughly, is Revelation.

There are various ways of filling out Revelation. Here are three. Mark Johnston says that, on Revelation, "[t]he intrinsic nature of canary yellow is fully revealed by a standard visual experience of a canary yellow thing" (1992: 223). Johnston

\footnotetext{
${ }^{22}$ We say 'live' because P-Essentialism is incompatible with sense datum theories. We do not know of any current sense-datum theorists, but it's not clear if sense-datum theories are theories of perceptual experience anyway. There is a common reading where they are just theories of what we are most immediately acquainted with in experience. In that case, ruling out sense-datum theory would support the modest position.
} 
does not say what 'fully revealed' comes. But a reasonable idea is this: for the intrinsic nature of canary yellow to be fully revealed in experience, it is necessary to be conscious of the essential features of canary yellow as essential features. ${ }^{23}$

Byrne and Hilbert (2007: 77), by contrast, focus on two claims:

Self-Intimation If it is in the nature of the colors that $p$, then after careful reflection on color experience it seems to be in the nature of the colors that $\mathrm{p}$.

Infallibility If after careful reflection on color experience it seems to be in the nature of the colors that $\mathrm{p}$, then it is in the nature of the color that $\mathrm{p}$.

Revelation, according to Byrne and Hilbert, is the conjunction of Self-Intimation and Infallibility.

Finally, let Revelation Light be this claim: we are conscious of the essential p-features of $\mathrm{p}$-colors in virtue of having an experience of color. Revelation Light follows from Essential Features.

Revelation Light is the most plausible of these accounts. Color scientists try to tease out the essential $\mathrm{p}$-features of p-colors by carefully considering what people seem to see, under all sorts of conditions, when they have experiences of p-colors. This investigation shows that, as explained earlier, every p-color has a hue, a saturation and a lightness, which are essential to it. Furthermore, the investigation shows that some hues are binary (e.g. every orange is to some degree reddish and to some degree yellowish) and some hues have unique instances (e.g., for a normal observer there is a red that is neither yellowish or blueish). The upshot is that it takes work to discover that the essential features of p-colors are essential features. So simply experiencing a p-color would be enough to reveal its essential features, but not enough to fully reveal them-i.e., reveal them as essential features-which Johnston's account seems to imply. That is, when color scientists are analyzing pcolors, they are assuming that the essential features of p-colors are part of our

\footnotetext{
${ }^{23}$ Although Johnston's initial statement of Revelation employs 'intrinsic', he later also employs 'essential' (1992: 139). Johnston eventually gives up Revelation though, albeit begrudgingly.
} 
experiences of p-colors; but they are not assuming that these essential features are readily apparent as essential features. Of course this is what Essential Features claims about p-colors. So Revelation Light, which follows from Essential Features, is a better account of p-color experience than Johnston's account. ${ }^{24}$

Regarding Byrne and Hilbert's take, Essential Features does not imply SelfIntimation if Self-Intimation is taken to imply consciousness that something is an essential feature. And Self-Intimation is a strong claim anyway; too strong, given the above considerations about the scientific investigation of color. The bigger issue though is Infallibility. From I-Claim p-colors seem to be properties of objects. Thus by Infallibility it is part of the very nature of p-colors that they are properties of objects. But clearly that's false-just consider perceptual illusions and hallucinations. Furthermore, scientists who are (implicitly) using something like Revelation to investigate the nature of p-colors do not assume that p-colors are properties of objects. Hardin (1988: 111), who is well-known for his study of the science of p-colors, is explicit on this point. And some color scientists are also explicit in their rejection of the claim that p-colors should be assumed to be properties of objects. ${ }^{25}$ So the Byrne and Hilbert account of Revelation, interpreted as a thesis about p-color, is not plausible. But Essential Features works well.

These points do not directly support the modest position. But they do support it indirectly, by showing how our theory's auxiliary claim-Essential Featuresdoes not imply anything obviously implausible about p-color. For if it did, we would have less reason to believe our theory, and as result, anything it might imply, or not imply, about experiences and their objects.

\section{A Plea for Modesty}

For the past twenty-five years, the transparency of experience has been the central point of theoretical contention in the philosophy of perception. If this is hyperbole,

\footnotetext{
${ }^{24}$ For the (implicit) use of Revelation in scientific investigations of color, see Boynton (1979: 30-31) and Hurvich (1981: 3-11).

${ }^{25}$ Here are three examples: Boynton (1979: 26-7); Zeki (1983: 764); Palmer (1999: 95, 97).
} 
it's barely so. The core idea is not obviously new (fn. 2), but Harman's Eloise was galvanizing. And we believe that the attention afforded to transparency is a good thing, since the phenomenon is important. But our view is that its importance lies not in what it tells us about perceptual experiences-it doesn't really tell us anything - but in what it can tell us about the objects of experience.

Our argument for this modest meta-theoretical position and against the optimistic position had two prongs. The first focused on Tye's transparency theory. We argued that (i) Tye's theory is flawed, and that (ii) even if it were not flawed-even if Tye's argument for P-Externalism were compelling-Tye's theory is plausibly seen as telling against the optimistic meta-theoretical position, and in favor of the modest position. The second prong focused on developing a new transparency theory that does not suffer from the flaws of Tye's theory, yet also favors the modest position. So what we have tried to do is make the prima facie case for the modest meta-theoretical position more robust. Transparency should encourage only modesty about experiences. We leave it to the reader to determine if our plea for modesty should be heeded. ${ }^{26}$

\section{References}

[1] Averill, Edward W. (1992). The Relational Nature of Color. Philosophical Review 101 (3): 551-88.

[2] Averill, Edward W. (2005). Toward a Projectivist Account of Color. Journal of Philosophy 102 (5): 217-34.

[3] Aydede, Murat. (2009). Is feeling pain the perception of something? Journal of Philosophy 106 (10): 531-567.

[4] Block, Ned. (1996). Mental Paint and Mental Latex. Philosophical Issues 7:19-49.

\footnotetext{
${ }^{26}$ For very helpful comments, we thank three anonymous referees for Erkenntnis.
} 
[5] Block, Ned. (2003). Mental Paint. In M. Hahn and B. Ramberg (eds.), Reflections and Replies: Essays on the Philosophy of Tyler Burge. Cambridge, MA: MIT Press.

[6] Boghossian, Paul \& David Velleman. (1989). Color as a Secondary Quality. Mind 98 (January): 81-103.

[7] Boynton, R. (1979). Human Color Vision, Holt, Rinehart and Winston.

[8] Byrne, Alex \& Heather Logue. (2008). Either/Or. In Adrian Haddock \& Fiona Macpherson (eds.), Disjunctivism: Perception, Action, Knowledge. Oxford University Press. pp. 314-319

[9] Byrne, Alex, \& David R. Hilbert. (2007). Color Primitivism. Erkenntnis. 66 (1): 73-105.

[10] Byrne, Alex. (2011). Experience and Content. In Katherine Hawley \& Fiona Macpherson (eds.), The Admissible Contents of Experience, pp. 6082. Wiley-Blackwell.

[11] Cohen, Jonathan. (2011). The Red and the Real: an Essay on Color Ontology. Oxford University Press.

[12] Crane, Timothy. (2006). Is there a perceptual relation? In T. Gendler \& J. Hawthorne (eds.), Perceptual experience. Oxford: Oxford University Press.

[13] Frey, Christopher. (2013). Phenomenal Presence. In Uriah Kriegel (ed.), Phenomenal Intentionality. Oxford University Press.

[14] Gottlieb, Joseph. (2016). Transitivity and Transparency. Analytic Philosophy. 57 (4): 353 - 379.

[15] Gow, Laura. (2016). The Limitations of Perceptual Transparency. The Philosophical Quarterly 66 (265): 723-744.

[16] Gupta, Anil. (2012) An Account of Conscious Experience. Analytic Philosophy 53: 1-29.

[17] Hardin, C.L. (1988). Color for Philosophers. Hackett.

[18] Harman, Gilbert. (1990). The Intrinsic Quality of Experience. Philosophical Perspectives 4: 31-52. 
[19] Hurvich, L. (1981). Color Vision. Sinauer Associates.

[20] Johnston, Mark. (1992). How to Speak of the Colors. Philosophical Studies 68 (3): 221-263.

[21] Kind, Amy. (2003). What's So Transparent about Transparency? Philosophical Studies 115: 225-244.

[22] Martin, M.G.F. (2002). The Transparency of Experience. Mind and Language 4 (4): 376-425.

[23] McGinn, Colin. (1983). The Subjective View. Oxford University Press.

[24] Molyneux, Bernard. (2009). Why Experience Told Me Nothing About Transparency. Nous 43 (1): 116-136.

[25] Moore, G.E. (1922). The Refutation of Idealism. In Philosophical Studies, London: Kegan Paul.

[26] Pautz, Adam. (2007). Intentionalism and perceptual presence. Philosophical Perspectives 21 (1): 495-554.

[27] Palmer, S. (1999). Vision Science. MIT Press

[28] Pelczar, Michael. (2015). Sensorama: A Phenomenalist Analysis of Spacetime and Its Contents. Oxford University Press.

[29] Schroer, Robert. (2007). Reticence of Visual Phenomenal Character: A Spatial Interpretation of Transparency. Australasian Journal of Philosophy 85 (3): 393-414.

[30] Shoemaker, Sydney. (1994). Phenomenal Character. Nous 28 (1): 21-38.

[31] Smith, A.D. (2008). Translucent Experiences. Philosophical Studies 140 (2): 197-212.

[32] Speaks, Jeff. (2014). What are debates about qualia really about? Philosophical Studies 170 (1): 59-84.

[33] Stoljar, Daniel. (2004). The Argument from Diaphanousness. In M. Escurdia, Robert J. Stainton \& Christopher D. Viger (eds.), "Language, Mind and World": Special Issue of the Canadian Journal of Philosophy. 34(Supp. 1): 341-390. 
[34] Tye, Michael. (1995). Ten Problems of Consciousness: A Representational Theory of the Phenomenal Mind. MIT Press.

[35] Tye, Michael. (2000). Consciousness, Color, and Content. MIT Press.

[36] Tye, Michael. (2009). Consciousness Revisited: Materialism without Phenomenal Concepts. MIT Press.

[37] Tye, Michael. (2014a). Transparency, qualia realism and representationalism. Philosophical Studies. 170: 3957.

[38] Tye, Michael.(2014b). Speaks on Strong Property Representationalism. Philosophical Studies 170 (1): 85-86

[39] Wright, Wayne. (2003). Projectivist Representationalism and Color. Philosophical Psychology 16 (4): 515-529.

[40] Zeki, S. (1983). Color coding in the cerebral cortex: the reaction of cells in the monkey visual cortex to wavelengths and colours. Neuroscience 9: 74165 . 